\title{
INFORMAÇÃO: \\ DO TRATAMENTO \\ AO ACESSO \\ E UTILIZAÇÃO
}

\section{A aquisição do conhecimento se dá através da busca de informações. É por isso que conhecer o que é a linguagem documentária e saber como utilizá-la adequadamente é fundamental para o educador.}

No quadro múltiplo e fragmentado da sociedade atual, a Informação, de maneira geral, assume grande importância. Quando nosso tempo de trabalho e de lazer parece ir diminuindo, frente a inúmeras solicitações, evidencia-se a necessidade crescente de mecanismos cada vez mais eficazes para a obtenção de informações.

Em linhas gerais, dizemos que a informação é utilizada para atualizar conhecimentos, para permitir o avanço nas diversas áreas de conhecimento, para divulgar novas idéias, para promover, enfim, a comunicação entre os homens.

Sem muita dificuldade observamos que o volume de informações de toda sorte

dificulta o acesso das pessoas. Em cada área de conhecimento impõe-se não apenas identificar as informações, mas acima de tudo ter critérios que permitam fazer recortes significativos no conjunto da produção da área, pois existem linhas de orientação diversas, informações de qualidade diversas, interesses de vários níveis, que dificultam o acompanhamento da produção de informação, até mesmo entre especialistas.

Em que pese esta dificuldade de seleção, não se pode negar que a informação, entendida de forma ampla, se constitui, na sociedade moderna, num objeto de primeira necessidade, capaz de mudar nosso rumo pessoal e de modificar a vida em sociedade.

Como é natural, a frequiente e diversificada utilização do termo informação vem gerando grande variação conceitual, sendo

AS AUTORAS

Maria de Fátima Gonçalves M. Tálamo Prof. Doutora do Departamento de Biblioteconomia da ECA-USP.

Anna Maria Marques Cintra Prof. Doutora do Departamento de Biblioteconomia da ECA-USP.
Nair Yumiko Kabashi Prof. Doutora do Departamento de Biblioteconomia da ECA-USP.

Marilda Lopes Ginez de Lara Assistente do Departamento de Biblioteconomia da ECA-USP. mesmo permitido dizer que temos hoje vários sentidos para essa palavra, ou até mesmo dizermos que há várias palavras com a forma informaçâo. 
Em estudo anterior, Cintra et alii (1994), consideramos que a relação informação/conhecimento poderia ser observada a partir de aspectos complementares. Neste trabalho ressaltamos que esses aspectos recobrem eixos definitórios de "informação" e "conhecimento".

Assim,

"conhecimento" é um estoque, ou conjunto de saberes acumulados, enquanto "informação" é um fluxo de mensagens;

o "conhecimento" se apresenta como algo estruturado, coerente e, freqüentemente, universal, enquanto a "informação" é atomizada, temporária, efêmera.

Na sociedade atual não só podemos observar que o conjunto de conhecimentos de um indivíduo e da sociedade é alterado com a "entrada" de novas informações, que provocam adições, reestruturações ou mudanças, como também que há, por força do volume de informações que se apresenta em cada área, uma significativa mudança na forma de conhecer.

Como assinala Moles (1967), o conhecimento atual se assemelha mais a um feltro, onde as informações são prensadas, do que a um tecido, onde os fios formam uma trama organizada. É em função disso que o homem moderno sabe muito pouco sobre muita coisa.

Para evitar que o conhecimento produzido se perca, ou mergulhe num caos onde nada possa ser recuperado, torna-se necessária a criação e a adoção de sistemas de registro capazes de propiciarem o compartilhamento de saberes entre pessoas.

Entre as várias formas de registro destacamos o livro, a imagem expressa em fotos, gravuras, quadros etc., o jornal, a revista, o disco, o vídeo e outros suportes magné- ticos que, por conterem algum tipo de informação, se constituem em documentos.

Considerando, pois, a grande quantidade de documentos que atestam hoje o estágio de desenvolvimento de nossa sociedade, com facilidade percebemos a necessidade de sistemas de tratamento dessa massa documental, para que ela possa ao mesmo tempo ser divulgada e servir de matéria prima para novos conhecimentos.

É em função desta necessidade que nasce o papel fundamental da Análise Documentária, área que cuida especificamente da representação da informação, para que ela possa ser adequadamente guardada e devidamente encontrada, quando se fizer necessário.

Com apenas um pequeno esforço intelectual podemos perceber que não existem mecanismos capazes de dimensionar nem com exatidão, nem próximo à exatidão a quantidade de conhecimentos acumulados no mundo moderno. Inúmeras obras de referência (livros, revistas, catálogos etc.) tentam auxiliar a recuperação de informação, servindo para minimizar fenômenos corriqueiros como o da "redescoberta científica", que podem pôr em risco muita pesquisa, caso os centros produtores de conhecimento não disponham de formas de intercomunicação.

Tudo indica que, sem sistemas potentes de informação, a sociedade tenderá à redescoberta de muitos fenômenos já conhecidos e dominados, gerando forte limitação ao desenvolvimento do conhecimento humano,

ao mesmo tempo em que se dará um grande desperdício de recursos humanos e materiais.

Outro fenômeno que atesta a necessidade de bons recursos no campo da guarda 
e recuperação da informação vem do alto nível de especialização atingido por algumas áreas, o que provoca também alto grau de obsolescência da informação.

É bem verdade que o mundo moderno atravessa uma fase de busca de relações, mais nomeadas que vividas, de interdisciplinaridade e multidisciplinaridade, reflexos das tendências também desgastadamente nomeadas como pós-modernidade, onde os limites entre as áreas de conhecimento ficam tênues.

Neste contexto, a análise documentária não pode mais se ater a sistemas de classificação rígidos, inflexíveis, em que o universo de conhecimentos pré-estabelecidos determina o lugar do documento, sem muitas possibilidades de cruzamentos.

Daí o interesse pela Análise Documentária, uma vez que através dela é feita a descrição do conteúdo do documento e sua tradução numa linguagem construída especialmente para este fim.

Entretanto é preciso considerar que as linguagens documentárias podem ser construídas a partir da linguagem natural, o que gera entre elas uma relação simultânea de aproximação e distanciamento, bastante característica.

Enquanto a linguagem natural é um sistema de formas, que supõe, entre outras coisas, um trabalho de construção do vivido, as Linguagens Documentárias são sistemas construídos a partir da linguagem natural, mas profundamente restritivos, por estarem vinculadas à organização da informação.

$\mathrm{Na}$ prática a linguagem natural expressa a tendência original do homem de compreender, governar e modificar o mundo. Também as Linguagens Documentárias buscam alguma forma de compreensão e de "governo", sem, no entanto, chegar ao nível da modificação, da transformação do mundo, já que não dispõem de um mecanismo criador.

Assim, a linguagem natural opera com estruturas que são, simultaneamente, estáticas e dinâmicas e que permitem "a fixação de cada aparência dentro do esquema geral de referência, ao mesmo tempo que deixa espaço para que essa mesma aparência surja num outro ponto do quadro, a partir de outras relações, repetindo o mesmo processo" (Cintra et alii, 1994:19).

De fato,

as linguagens documentárias operam com estruturas estáticas que permitem a representação de inúmeros documentos,

a partir dos mesmos parâmetros, para que se garanta a forma de estocagem e recuperação da informação.

Essa tarefa supõe que o vocabulário das linguagens dos documentos tenha sido submetido a uma sistematização. Este vocabulário sistematizado denominado terminologia (por exemplo, a do campo da Biologia, da marcenaria, do esporte, etc...) é base importante para o trabalho documentário, porque permite que se opere, de início, com significados estáveis e reconhecidos em cada área.

Assim, áreas do conhecimento que não dispõem de uma terminologia assentada, constituem problemas para a Documentação. Desse modo, as Linguagens Documentárias de áreas como as Ciências Sociais, por exemplo, tendem a refletir a própria natureza nem sempre sistemática do seu domínio.

Outro aspecto a ser considerado diz respeito à eficiência das Linguagens Documentárias. Essa eficiência depende do grau de adequação à literatura tratada e aos objetivos da instituição e de seu usuário. Assim 
sendo, as linguagens que procuram abarcar todo o universo do conhecimento são mais gerais e, via de regra, reproduzem uma organização do conhecimento já mais cristalizada. Por seu lado, Linguagens Documentárias especializadas em determinados domínios tendem a ser mais detalhadas e procuram refletir os estágios de desenvolvimento do domínio específico.

As Linguagens Documentárias mais conhecidas (e muito utilizadas no Brasil) são os sistemas decimais de classificação, de natureza enciclopédica. Elas orientam tanto a distribuição dos livros e documentos nas estantes e/ou arquivos de Bibliotecas, como determinam as formas de entrada (acesso por assunto) dos mesmos nos catálogos colocados à disposição do público.

Em sua maioria, tais linguagens têm como ponto de partida disciplinas já consolidadas como a Filosofia, a Religião, as Ciências Sociais, as Ciências Puras, as Ciências Aplicadas, a Literatura, a História e a Geografia, que se subdividem, por sua vez, em sub-disciplinas e assuntos. Muito utilizadas em bibliotecas que contam com acervos amplos, essas linguagens fornecem pistas, indicações para o assunto que se procura mas, na prática, uma boa parte do trabalho de seleção de documentos fica por conta do próprio usuário, face ao grau de generalidade com que neles são tratados os assuntos.

Em sistemas informacionais especializados, as Linguagens Documentárias gerais são substituídas por linguagens voltadas para domínios específicos. Nestes casos, a Linguagem Documentária se impõe, principalmente, como instrumento para recuperação (localização) de referências bibliográficas sobre determinados assuntos, não sendo utilizada para a organização física de documentos (que podem ser arranjados, por exemplo, pela cronologia de entrada na Biblioteca).
Desta maneira, embora não seja possível recuperar exatamente o documento que contém a informação desejada, mas sim a classe dos documentos que tratam do tema, os assuntos dos documentos estão representados de forma mais específica. Por exemplo, através de uma Linguagem Documentária da área de Demografia pode-se representar documentos sobre Nupcialidade, Fecundidade, Migração, etc. e, mais detalhadamente ainda, "costumes matrimoniais", "endogamia", "planejamento familiar", "migração sazonal", etc.

As pesquisas mais recentes sobre Linguagens Documentárias têm procurado ressaltar a importância do rigor tanto na construção e escolha de tais linguagens como no seu uso. Nesse sentido, a Terminologia dos domínios assume papel importante como fonte de referência para a organização dos conceitos, uma vez que a comunicação, através de Linguagens Documentárias, é sempre realizada por meio de conceitos.

Outra fonte de referência importante é a linguagem do usuário do sistema de informação. Ao selecionar as unidades que comporão o vocabulário das Linguagens Documentárias é preciso considerar, à exaustão, o modo pelo qual o usuário se refere ao universo informacional, de modo que a própria Linguagem Documentária reflita de fato essa disposição que propicia que o usuário reconheça sua própria linguagem na organização da informação.

Pode-se afirmar, portanto, que

as Linguagens Documentárias funcionam como instrumentos intermediários, através dos quais se traduz, de forma sintética, as informações contidas em textos, ou as perguntas dos usuários, para a linguagem do sistema documentário. 
Dito de outro modo, uma LD é utilizada na entrada do sistema, quando o documento é analisado para registro e armazenamento. Seu conteúdo é identificado e "traduzido" de acordo com os termos da Linguagem Documentária utilizada. É da mesma forma utilizado à saída do sistema quando, a partir da solicitação da informação, é feita a representação da pergunta, isto é, o pedido é analisado, seu conteúdo identificado e devidamente "traduzido" nos termos da LD utilizada.

Estruturalmente a Linguagem Documentária é composta de um léxico, de uma rede paradigmática e de uma rede sintagmática. O léxico é identificado como uma lista de termos descritores (termos preferenciais), devidamente filtrados e depurados e de termos não-descritores; a rede paradigmática explicita as relações essenciais, e geralmente estáveis, entre descritores, enquanto a rede sintagmática estabelece uma gramática de combinação dos descritores (Cintra et al. 1994).

Diferentemente, porém, da Linguagem Natural, o sistema de relações das Linguagens Documentárias não é virtual. Ao contrário, os elementos dessa linguagem são selecionados de universos específicos, seu sistema de relações é construído e seu uso requer a existência de regras explícitas. Por esse motivo, as Linguagens Documentárias são linguagens construídas.

Cada Linguagem Documentária procura, por sua vez, dar conta de esferas particulares do real. Assim, o sistema de relações de cada linguagem determina um lugar específico para cada um de seus termos, fixando, desse modo, os seus significados específicos no interior do sistema.

As linguagens construídas, face à função que devem desempenhar na representação e na recuperação da informação docu- mentária, exigem formulações de sentido rigorosas. Isso porque a condição para se obter resultados positivos na busca de informação é que a pergunta e a resposta sejam formuladas no mesmo sistema. É fácil perceber, desse modo, que a Linguagem Documentária deve se constituir de relações unívocas entre significante e significado.

Vale lembrar que,

isoladas, as palavras não têm significado ou podem ter todos os significados possíveis. É só no discurso que as palavras assumem significados particulares.

Embora organizadas de forma relacional, as unidades das Linguagens Documentárias são desvinculadas dos contextos onde aparecem, podendo, desse modo, tornaremse ambíguas.

É preciso ainda ressaltar que, para realizar com eficácia as funções de intermediação, as Linguagens Documentárias pressupõem o controle sobre o vocabulário, isto é, o controle da fonte de significação. Esse controle é necessário para que a cada unidade preferencial integrada numa Linguagem Documentária corresponda um conceito. Metodologicamente, recorre-se às Terminologias de modo que as unidades das Linguagens Documentárias assumam significados vinculados a sistemas de conceitos determinados. Confere-se, desse modo, referência às palavras, que passam a significar, segundo determinados sistemas conceituais, interpretações pertinentes.

Além disso, a estruturação lógico-semântica das Linguagens Documentárias é fundamental. Sua estrutura básica é dada através das relações hierárquicas, não-hierárquicas e de equivalência.

Uma vez elaboradas e postas em uso, as LDs são atualizadas mediante operações 
de supressão de termos em desuso, reagrupamento de descritores ou adição de termos novos. Só assim as Linguagens Documentárias se mantêm como instrumentos dinâmicos capazes de acompanhar os avanços do conhecimento materializados nos textos.

\section{CONSIDERAÇõES FINAIS}

A necessidade crescente de o aluno, desde as séries iniciais, ser instrumentalizado para obter e organizar informação (normalmente denominada pequisa) não prescinde de um conhecimento específico do modo de organização da própria informação nas fontes em que é registrada. Como esse "modo" não faz parte da experiência imediata do aluno, é preciso que conteúdos programáticos integrem itens específicos do manejo de bibliotecas e demais fontes de referência que assegurem ao aluno qualificarse como usuário de informação.

Nesse sentido,

ao professor, independente da sua área de atuação, solicita-se o domínio do conhecimento mínimo para "navegar" no universo da informação.
Desse modo, a compreensão da natureza e da função da Linguagem Documentária é fundamental.

De fato, ao lado do ensino de outras linguagens, a Linguagem Documentária deve ser objeto de aprendizado específico. Com isso, o professor deixa de ser apenas um transmissor de conhecimento para juntar às suas funções a de orientador na busca, ordenação e avaliação do conhecimento.

\section{BIBLIOGRAFIA}

CINTRA, A.M.M et al. Para entender as linguagens documentárias. São Paulo: Ed. Polis, 1994.

FRANK, H. (1970) Informação e Pedagogia. In: Cahiers de Royaumont. O Conceito de Informação na Ciência Contemporânea. Rio de Janeiro: Paz e Terra. p. 127-153.

MOLES, A. (1967). Sociodinâmica da cultura. São Paulo: Perspectiva/Editora da USP, 1974.

WADDIGTON, C.H. (1977) Instrumental para o pensamento. Belo Horizonte/São Paulo: ItatiaiaEDUSP. 